\title{
Embracing Wired Networks
}

\section{geek@home}

Mache Creeger, Emergent Technology Associates

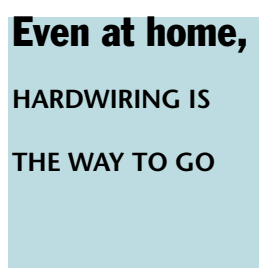

do it right, and then forget about it. I want a low-cost network infrastructure with guaranteed availability, bandwidth, and security. If these attributes are important to you, Wi-Fi alone is probably not going to cut it.

People see hardwiring as part of a home remodeling project and, consequently, a big headache. They want convenience. They purchase a wireless router, usually leave all the default settings in place, hook it up next to the DSL or cable modem, and off they go. Ease and convenience are the selling points, but there are certainly tradeoffs to consider. As the IT expert of last resort for family, friends, and sometimes their family and friends, here are some of my experiences with Wi-Fi in the home.

\section{ACCESSIBILITY AND AVAILABILITY}

Wi-Fi signals usually do not reach every area of the home, or if they do, sometimes the service can be intermittent because of RF noise or conflict. As luck would have it, those areas are typically the most important: the home office, the master bedroom, or the kids' rooms. Often the culprit is too many walls or a wall that is too dense in the straight line between the router and its destination. A wireless telephone or microwave oven can sometimes be in conflict with the same unlicensed RF spectrum.

Usually Dad is dispatched to kludge together some kind of compromise. This typically means changing the router and/or client computer position to lessen outside interference and/or capture some finger of the transmitted Wi-Fi signal. Those who are more sophisticated will purchase a wireless access point, placing it at some midpoint to capture, amplify, and resend the signal, adding latency and decreasing bandwidth. As a last resort, the truly brave will string a long patch cable from the router to the problem area, usually to the horror of the significant other required to live with cables snaking along the baseboards.

Security. Most people use either no security at all or WEP (Wired Equivalent Privacy). More often than not they just plug the unit in and use it with the default settings. As a result, the majority of wireless LANs can be easily compromised. Just take a look at the scary discussions about how quickly a free utility called Aircrack can make an outside laptop a peer on a WEP-secured LAN. ${ }^{1}$

A quick scan of the surrounding homes in my relatively sophisticated Silicon Valley neighborhood showed a total of 14 operating Wi-Fi routers visible from the router in my closet. Even though WPA (Wi-Fi Protected Access) is currently considered to be the best available WiFi security paradigm, only one was using it. The rest were either open or secured by WEP.

Why should you care? Not only do you want to surf the Internet in private, but you do not want unauthorized people using your Internet account or rummaging through your private information (think e-mail, medical records, tax returns, Quicken files, and PayPal and eBay passwords). Perhaps more importantly, you do not want to be liable to organizations like the RIAA (Recording Industry Association of America) for illegally downloading copyrighted material.

Bandwidth. Wi-Fi routers are rated at certain speeds, but the actual realized bandwidth is much less. The most popular standard, $802.11 \mathrm{~g}$, is rated at 54 megabits per second, but the effective rate realized in the real world is closer to 20-25 Mbps. These speeds are adequate for Web browsing and e-mail but are not nearly enough for home media, remote file sharing, or moving large files between machines. Newer, faster standards than $802.11 \mathrm{~g}$ are now starting to take hold.

Cost. While most laptops and desktops produced today have Wi-Fi built in, older machines do not. Wi-Fi has only recently become standard on desktop machines. To become wireless, older systems will require the purchase, installation, and configuration of an additional Wi-Fi card. In my house everyone has his or her own computer, and I expect that my family is fairly typical. An upgrade to wireless would probably cost around $\$ 50$ plus installation and configuration time for each older computer. 
The promise of Wi-Fi providing secure, available, and adequate network bandwidth anywhere in the home depends on what secure, available, and adequate mean to you. Wi-Fi plays on the fears that installing wiring in the home will cause great pain and cost, but many folks overlook the baggage that Wi-Fi brings with it. In my experience, what Wi-Fi really provides is limited network bandwidth, good for e-mail and Web browsing but not much else; it is easy to set up, but provides networking that is usually not very secure and is limited to unobstructed and interference-free environments.

\section{WIRED INFRASTRUCTURE}

With a wired infrastructure, you get a network utility that is highly available and full bandwidth (up to 1 gigabit per second, with $10 \mathrm{Gbps}$ on the horizon). With access requiring a physical connection, security issues are limited to the capabilities of the firewall inside the router.

The wired infrastructure I built in my home centralizes all the wired services from wherever they enter the home to the central wiring closet. From there I project those services to other places around the house. This works not only for network services, but also for phone, alarm, audio, and video.

The cost of a wired infrastructure can be divided into two areas: the cost of the equipment, which is relatively inexpensive; and the cost of the installation, which can be variable depending on the architecture of your home and your skill set. You need network cable, a way to terminate the cable both at the central wiring closet and at the remote location, devices such as routers and network switches to centrally support and distribute services to the remote locations, and patch cables to attach those devices to the wiring infrastructure.

Cable. At a minimum, you should use CAT5e-rated UTP (unshielded twisted pair) cable. Its most economical form is a box with a 1,000-foot roll. Since the type of cable directly impacts overall performance and how long it will remain useful, I upgraded the cable in my home to one that is rated at 350 megahertz and is relatively immune to the kinks and twists that can occur during installation. Standard CAT5e cable typically costs around $\$ 50$ per box, while the cable in my home costs a little under $\$ 200$ per box. ${ }^{2}$ In most cases one 1,000-foot box should suffice for an entire house.

Wire closet terminations. New or used 110-format punch-down or patch panels, rated CAT5e or greater, are relatively inexpensive and can terminate each UTP cable connecting a remote location to the wiring closet. They typically cost between $\$ 50$ and $\$ 100$. To connect the cable to either one of these panels, you may need to borrow or purchase a 110-format punch-down tool that forces each of the eight UTP wires into the panel connector. ${ }^{3}$ From the panel you can connect each remote location to a network switch with a small patch cable.

It is important to keep the signals on each wire on a cable consistent through the connection. That means that each of the color-coded eight wires of a UTP cable must be attached to the same RJ45 connector pin on both ends of the cable. The assignment of each of these wires to a specific connector pin is defined by a standard. For my installations I stick to the 568A standard. ${ }^{4}$

Remote terminations. For remote network outlets in other rooms, most connector vendors ${ }^{5}$ have a range of faceplate options that fit a standard-size, single-gang, plastic, old work outlet box ${ }^{6}$ and range from one to six

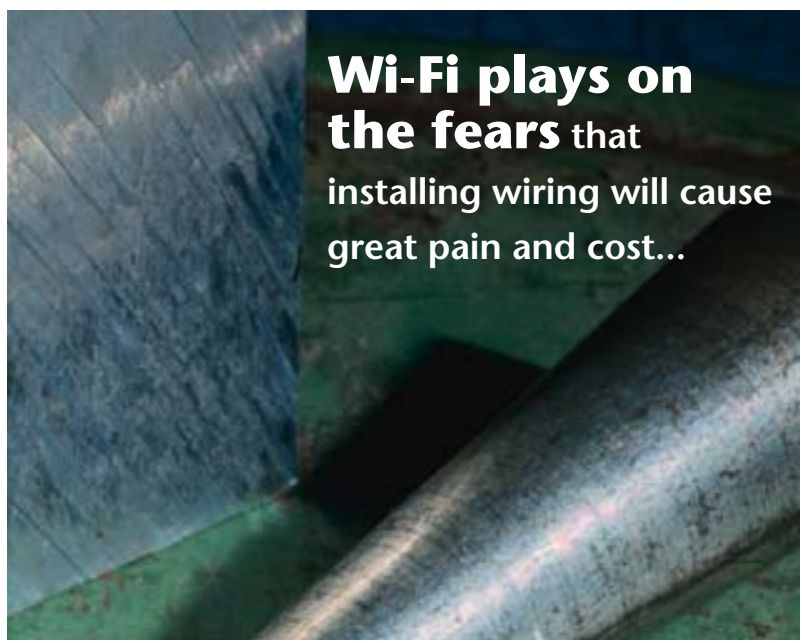

connectors. Along with the normal CAT5e or better RJ45 network connector, the options include RJ11 telephone connectors, as well as RCA, F, and BNC coax connectors for audio and video.

\section{INSTALLATION}

Running cabling from a central location to a room outlet is the major challenge of installing a wired network. It requires some creativity in planning a path to get to its destination unseen. Ethernet allows for a cable length of up to 100 meters (328 feet). Taking a more roundabout route that allows the cable to remain hidden is encouraged and will rarely impact performance. The only rule is to avoid running parallel to a power cable. Either keep parallel runs at least three or four feet away or cross over them at a 90-degree angle.

Where to put the cable runs. My home is mostly one 
story with an unfinished attic above and an unfinished crawl area below the living space. Both of those areas are available as cable pathways from the wiring closet to any network outlet in my house. Because of easy access, I opted for the unfinished crawl area for my cable runs, using large drive rings ${ }^{7}$ (they are like big hooks) attached to exposed beams and floor joists every 18 inches or so to support the cable from the wiring closet to its destination directly underneath the room outlet.

To install a flush-mount room outlet, you must first make its location visible to the unfinished attic or crawl space. In my case, I gently removed the floor molding right below where I wanted to place the outlet and drilled a small signal hole through the floor directly next to the wallboard. I threaded a piece of wire through the hole so it was visible in the crawl area below and then cut a hole in the wallboard to accommodate the plastic workbox.

Back under the house the hanging wire became a guide to drill a one-inch hole through the flooring and into the empty space inside the wall. I inserted the cable into the hole and pushed it through so it was visible to the cutout in the wall in the room above. I then pushed the cable through the cutout and the opening in the back of a plastic workbox. The box could then be installed in the cutout flush to the wallboard. I attached the RJ45 connectors to the end of the cable and mounted them into the faceplate, which I then attached to the workbox in the wall. With the hanging wire removed and molding reinstalled, the signal hole was covered from view.

If you do not have an attic or crawl space, you do have other options for installing a flush- or surface-mount outlet in or on a wall. If you have wall-to-wall carpet, you can pull it off the tack strip that runs along the wall, place cable in the space between the tack strip and wall, and replace the carpet back onto the tack strip. Transitions across interior walls are easily done by drilling through the wall right at the level of the floor. If there are no carpets, you can try placing cable behind floor molding. Usually there is a space between the wallboard and the floor that will accommodate a cable. Similar strategies may work for door and ceiling molding. As a last resort, you can drill a hole through an exterior wall to the outside of your home, run wiring around the outside of the house under the eaves, and back through the wall to its final destination. Plug the holes with silicon caulk.

\section{INVEST INWIRE}

Wi-Fi poses accessibility, availability, and bandwidth restrictions, as well as privacy and liability risks that I find unacceptable to my home networking needs. I often won- der at the efforts and expense people will go to in order to avoid installing wires when it is obvious that wires are the best way to transmit information. If you look at any commercial setting, structured wiring is the primary networking platform; wireless is secondary. Given that home networking demands usually lag what is needed commercially, people should embrace wired networks for the home.

With cable and wire closet terminations available from $\$ 150$ and the parts costs for room outlets at between $\$ 5$ to $\$ 10$ per room, the equipment costs for hardwiring your home are relatively inexpensive. The variable is how difficult it is to hide the cable running from the wire closet to the room outlet. With minimal home improvement skills and a forgiving home architecture, a commercial-grade wiring plant can easily and inexpensively be installed to provide rock-solid and secure service to every room in your house. I see it much like the transition from terrestrial broadcast TV to cable TV. Given the increasing demands you will be making on your home network environment, investing in a wired infrastructure will eventually be as common as wiring for cable TV. Q

\section{REFERENCES}

1. http://www.google.com/search?hl=en\&q=aircrack\&btn $\mathrm{G}=$ Google+Search.

2. Belden Media Twist (part number 1872A) rated at CAT6 -; http://www.belden.com/pdfs/MasterCatalogPDF/ PDFS_links\%20to\%20docs/11_Networking/11.4.pdf.

3. I used a Harris-Dracon D-814 punch-down handle with a 110 punch-down blade.

4. See the definition of 568A and 568B UTP Cable Termination Standards at http://www.ablecables.com. au/568avb.htm.

5. These vendors include Lucent, Panduit, Leviton, and many others.

6. You can find old plastic workboxes at any home improvement center for around $\$ 1$.

7. I used $1 \frac{1}{4} 4$-inch drive rings priced at around 25 cents a piece.

\section{LOVE IT, HATE IT? LET US KNOW}

feedback@acmqueue.com or www.acmqueue.com/forums

MACHE CREEGER (mache@creeger.com) is a technology industry veteran based in Silicon Valley. He is the principal of Emergent Technology Associates, marketing and business development consultants to technology companies worldwide.

(c) 2007 ACM 1542-7730/07/0500 $\$ 5.00$ 